\title{
AMBIENTE MONTANHOSO E TURISMO EM PEDRO II, PIAUÍ
}

Iracilde Maria de Moura Fé Lima ${ }^{1}$ Antônio José Teixeira Guerra²

Resumo: Este artigo objetiva apresentar o planalto dos Matões, o ecoturismo e suas relações com a cultura do município de Pedro II, Piauí. Este planalto consiste numa cuesta secundária, moldada no reverso da cuesta regional da lbiapaba, na borda leste da Bacia Sedimentar do Parnaíba. Nesse ambiente montanhoso é crescente a visitação por apresentar paisagens naturais de beleza singular, além de atrativos culturais como o festival de inverno e o artesanato. Estudou-se as relações entre a estrutura geológica e as formas de relevo locais; as influências entre as paisagens naturais e a cultura para a atração turística. Utilizou-se revisão de literatura; trabalhos de campo; interpretação de mapas, fotografias e imagens de satélites trabalhadas em geoprocessamento. Identificou-se que o relevo local ainda guarda estreita relação com os elementos geológicos herdados do Mesozoico e que as paisagens locais favorecem a prática do turismo cultural e do ecoturismo.

Palavras chave: Planalto dos Matões. Morro do Gritador. Percée. Festival de inverno. Ecoturismo

\section{MOUNTAINOUS ENVIRONMENT AND TOURISM IN PEDRO II COUNTY, PIAUÍ}

Abstract: This paper aims to present the Matões' plateau, ecotourism and its relations with the culture in Pedro II Municipality Piauí State. This plateau consists of a secondary slope, shaped on the back of lbiapaba regional slope, on the eastern border of Parnaíba Sedimentary Basin. In this mountainous environment the visitation is growing for presenting natural landscapes of singular beauty, in addition to cultural attractions such as the Winter Festival and the handicraft. The relationships between the geological structure and the local relief forms were studied; and the influences between the natural landscapes and the culture for the tourist attraction. Was did the literature review; fieldwork; maps interpretation, photographs and satellite images processed in Geographic Information System - GIS. It was identified that the local relief still bears close relation with the geological elements inherited from the Mesozoic Period and that the resulting landscapes contribute to the practice of cultural tourism and ecotourism.

Keywords: Matões' plateau. Screamer's Gritador hill. Percé. Winter of Festival. Ecotourism

\section{AMBIENTE MONTAÑOSO Y TURISMO EN LA MUNICIPALIDAD DE PEDRO II, PIAUÍ}

Resumen: Este artículo tiene como objetivo presentar la meseta de los Matões, el ecoturismo y sus relaciones con la cultura de la municipalidad de Pedro II, Piauí. Esta meseta consiste en una cuesta secundaría, moldeada en el reverso de la cuesta regional de Ibiapaba, en el borde este de la Cuenca Sedimentar del Parnaíba. En este ambiente montañoso es creciente la visitación por presentar

\footnotetext{
${ }^{1}$ Universidade Federal do Piauí, Coordenação de Geografia, Teresina, Brasil, iracildemourafelima@gmail.com, https://orcid.org/0000-0003-3936-180X

${ }^{2}$ Universidade Federal do Rio de Janeiro, Departamento de Geografia, Rio de Janeiro, Brasil, antoniotguerra@gmail.com, https://orcid.org/0000-0003-2562-316X
} 
paisajes naturales de belleza singular, además de tractivos culturales como el Festival de Invierno y la artesanía. Se estudiaron las relaciones entre la estructura geológica y las formas de relieve locales; y las influencias entre los paisajes naturales y la cultura para la atracción turística. Se utilizó revisión de literatura; trabajos de campo; interpretación de mapas, fotografías e imágenes de satélites trabajados en geo procesamiento. Se identificó que el relieve local aún guarda estrecha relación con los elementos geológicos heredados del Mesozoico y que los paisajes resultantes contribuyen a la práctica del turismo cultural y del ecoturismo.

Palabras clave: Meseta de los Matões. Colina del Gritador. Percée. Festival de invierno. Ecoturismo

\section{Introdução}

O município de Pedro II se localiza na microrregião de Campo Maior, porção nordeste do estado do Piauí, tendo como ponto central de sua área urbana as coordenadas geográficas de $04^{\circ} 25^{\prime} 29^{\prime \prime}$ S. e $41^{\circ} 27^{\prime} 31^{\prime \prime} \mathrm{W}$ e altitude de $610 \mathrm{~m}$ (Figura 1). Encontra-se no compartimento de relevo Planalto Oriental da Bacia do Maranhão-Piauí (LIMA, 1987), apresentando uma área de 1.948 km², a uma distância de cerca de $200 \mathrm{Km}$ de Teresina, capital do Estado do Piauí. Contava em 2010 com uma população de 37.496 habitantes e apresentava um Índice de Desenvolvimento Humano municipal (IDHM) de 0,571 (IBGE, 2010).

Figura 1 - Localização do município de Pedro II no estado do Piauí
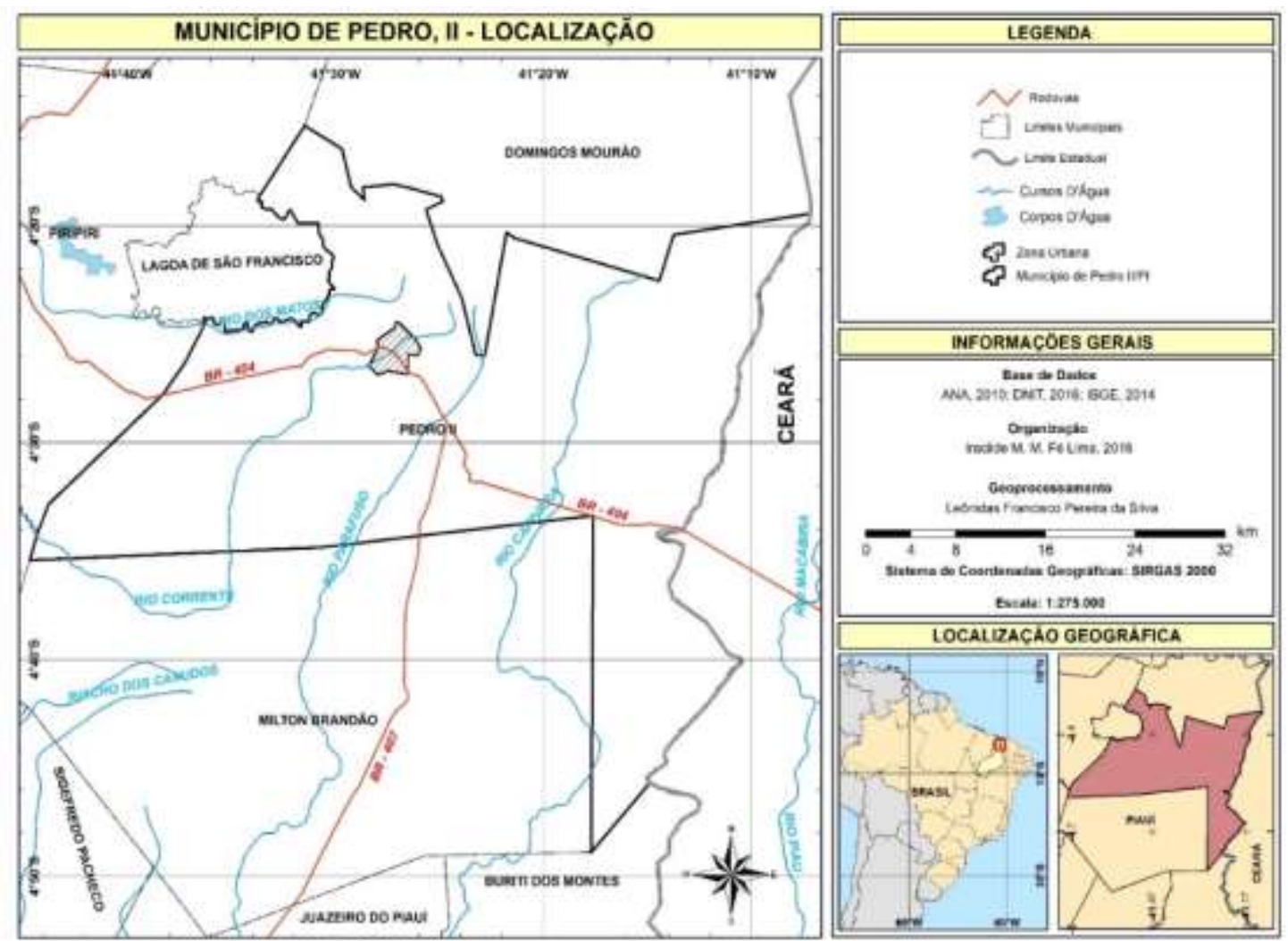

Base de dados: IBGE (2014). Org. Lima (2016). 
Em relação à sua localização na Bacia Sedimentar do Parnaíba, Pedro II encontra-se numa faixa da borda leste, solidariamente soerguida com o ombro oeste do rift Cariri/Potiguar (CLAUDINO-SALES, 2016), onde se formou a cuesta regional da Ibiapaba. Esta apresenta seu front voltado o estado do Ceará, e o reverso para oeste, seguindo o mergulho das camadas geológicas, no estado do Piauí. Esse front forma o limite dessa bacia sedimentar com a depressão ortoclinal, que corresponde a uma porção das Depressões Sertanejas Intermontanas modeladas no embasamento de rochas cristalinas (AB'SABER, 1969) (Figura 2).

Figura 2 - Perfil geológico-geomorfológico representando a evolução do relevo da cuesta regional da Bacia Sedimentar do Parnaíba

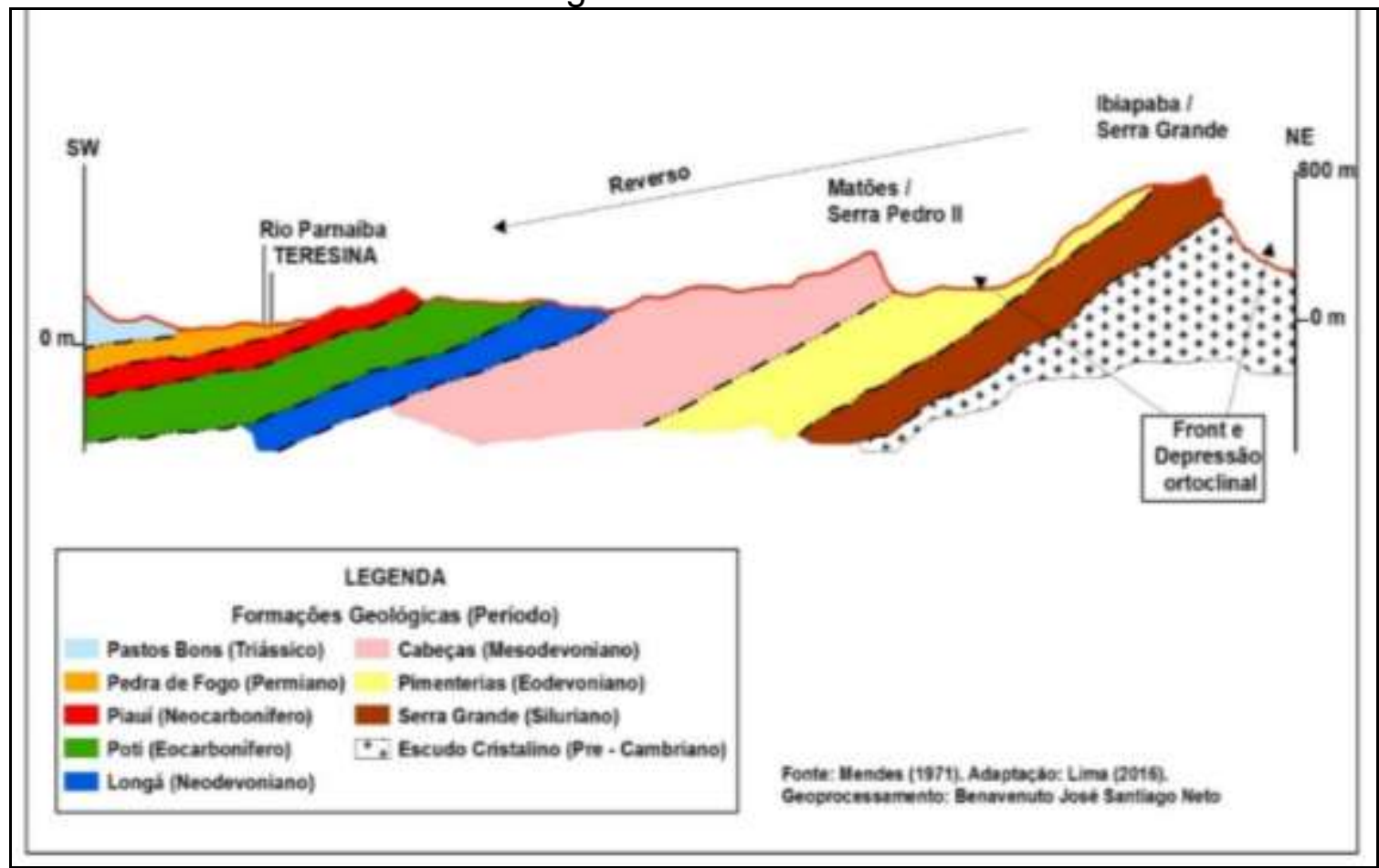

Fonte: Mendes; Petri (1971). Adaptação: Lima (2016).

Com a evolução milenar do Reverso da Ibiapaba, uma cuesta secundária se formou no seu trecho superior, conhecida localmente por Serra de Pedro II, ou Serra dos Matões, como resultado da intensa dissecação do reverso regional (ANDRADE; LINS, 1977). Dentre as formas de relevo modeladas nessa cuesta secundária destacam-se elevados topos, vertentes escarpadas e vales estruturais e fluviais, que refletem um acentuado controle por fraturamentos e também por uma composição litológica com níveis de resistência diferenciados aos processos erosivos. Estas condições de gênese e evolução das formas de relevo estão associadas ao soerguimento da borda da Bacia Sedimentar do Parnaíba e à reativação Mesozoica do Lineamento Transbrasiliano, uma vez que essa área se encontra na faixa afetada por eventos tectônicos (BRASIL, 1973; SAADI et al., 2005; MOURA-FE, 2016). 
Nessa área também se observa a ocorrência de intrusão de rochas básicas, formando diques e sills de diabásio/basalto, resultantes do tectonismo a que foi submetida essa bacia sedimentar no período Mesozoico (BIZZI et al, 2003). A acomodação dessas rochas intrusivas entre as formações geológicas Serra Grande e Pimenteiras (Siluriano/Eodevoniano) proporcionou condições hidrotermais locais responsáveis pelo desenvolvimento de um mineral raro nessa área: a opala (GOMES; COSTA, 1994; SACHS; BATISTA, 2015).

Desta forma, o conhecimento da base geológica se torna importante tanto para o estudo da organização e evolução do relevo e da drenagem, como também para a identificação de jazidas minerais e sua avaliação para exploração econômica. Todas essas condições do ambiente natural proporcionam atrações para visitação, principalmente de pontos mais elevados, como mirantes para contemplação da paisagem, desenvolvimento de atividades educativas e esportivas como rapel, banhos em cachoeiras e caminhadas (SANTIAGO, 2013). Também proporcionam um tipo de uso cotidiano singular pela população local: o encurtamento de caminhos entre comunidades do topo e da depressão ortoclinal, através de uma forma de relevo denominada percée, localmente conhecida como "o apertado da hora" (ACONTUR, 2016).

Essas características, associadas à ocorrência de temperaturas mais amenas, em relação às de outras áreas piauienses, em função da sua localização em altitudes entre $600 \mathrm{~m}$ e $800 \mathrm{~m}$, favorecem à exploração dessas paisagens como atrativos turísticos, conforme destacam Vieira et al. (2012). Essas amenidades climáticas motivaram, ainda, a realização anual de um grande evento cultural que ficou conhecido como Festival de Inverno: o Festival de Jazz e Blues de Pedro II, a partir de 2003 (GOMES, 2011).

Todos esses aspectos vêm atraindo nos últimos anos a esse município uma grande quantidade de visitantes piauienses e de outros lugares, despertando na população local o interesse pela atividade turística, demonstrado na renovação das próprias moradias, hotéis e pousadas, além da ampliação de suas atividades econômicas. Essa nova atividade desenvolvida a partir da revalorização do patrimônio natural e cultural, especialmente o relevo e a drenagem, o clima mais ameno e o artesanato de fios de algodão e de adornos da opala, tendo como ponto alto o festival de inverno, se bem planejada, certamente contribuirá para o desenvolvimento sustentável e para a elevação da autoestima da população local (PIAUÍ, 2002; GOMES, 2011). 
As referências sobre o município de Pedro II demonstram a importância que tem a ampliação do conhecimento sobre seu território e sua gente, envolvendo aspectos do ambiente natural, socioeconômicos e culturais. Nessa perspectiva, ao estudar as relações entre a estrutura geológica e as formas de relevo, destacou-se a utilização de uma percée chamada pelas comunidades locais de "o apertado da hora". Também identificou-se as influências que se estabelecem entre as paisagens naturais e a cultura para a atração turística nesse município. Assim, este trabalho teve como base a revisão da literatura e relatórios de trabalhos de campo; a leitura de mapeamentos temáticos do município de Pedro II, de imagens de satélites e de fotografias, utilizando técnicas de geoprocessamento.

Como principais conclusões identificou-se que a organização das atividades voltadas para o turismo cultural tem favorecido a intensificação do ecoturismo nesse município, sendo o morro do Gritador a principal atração da paisagem natural. Identificou-se também que a percée "o apertado da hora" se encontra em processo de evolução pelo recuo e alargamento, como resultado de fluxo fluvial, incidência de deslizamentos e queda de blocos no seu interior e que, mesmo assim, é utilizada frequentemente pela população local como caminho entre as localidades do topo e aquelas situadas na depressão ortoclinal, formada a partir da base do front da cuesta dos Matões.

Pesquisas sobre movimentos de massa têm diferentes objetivos, sendo um deles o de predizer sua ocorrência, que depende de diversos aspectos e, dessa forma, muito cuidado é necessário na interpretação das características do local que pode ser afetado (GUERRA, 2016). Assim, a intensificação do turismo nessa área pode aumentar riscos de deslizamentos, causando prejuízos à população local.

\section{Procedimentos Metodológicos}

Os procedimentos adotados neste trabalho corresponderam à realização do levantamento do referencial teórico, mapas e imagens sobre a área estudada, bem como relatórios de aulas de campo (LIMA, 2000; 2002; 2004; 2006; 2015; 2016). Durante as observações em campo foram realizadas entrevistas não estruturadas com os moradores e guias locais, ampliando as informações sobre características da área e sua relação com o uso da percée pela população. Como referencial específico sobre o turismo em Pedro II foram utilizados o Guia Turístico do Estado do Piauí (2002), os resultados da pesquisa de Gomes (2011) e informações sobre os 
visitantes fornecidas pela Associação de Condutores de Turistas e Visitantes de Pedro II (ACONTUR, 2016).

Para a sistematização dos dados, organização de mapas e gráficos e sua posterior análise, foram utilizadas imagens e mapas geológicos e hidrográficos, imagens e hipsometria do município de Pedro II. Essas imagens e cartas topográficas foram trabalhadas utilizando técnicas de geoprocessamento, tendo como base os bancos de dados disponíveis on-line da CPRM (2006), IBGE (2014) e TOPODATA (INPE, 2010), todos na escala de 1:250.000. Também foram utilizadas imagens do Google Earth Pro e a Carta): SB.24-A-II (n.746), na escala de 1:100.000 (DSG, 1973).

\section{Os Atributos Naturais das Paisagens Locais}

O município de Pedro II encontra-se no reverso da cuesta da lbiapaba, onde se destaca um front secundário, resultante da erosão diferencial das rochas que compõem as diferentes formações geológicas da Bacia Sedimentar do Parnaíba, cuja borda foi soerguida e intensamente fraturada (BIZZI et al, 2003; PIAUÍ/CPRM, 2006).

Os estudos sobre essa área e suas respectivas representações gráficas, indicam que o front principal da cuesta da Ibiapaba está moldado no Grupo Serra Grande que atinge altitudes de 800 até $900 \mathrm{~m}$ em alguns trechos de sua porção setentrional. $O$ front e o reverso imediato compõem-se predominantemente de conglomerados e arenitos, enquanto a depressão ortoclinal se moldou nas rochas cristalinas das depressões sertanejas do Nordeste semiárido (AB'SABER, 1969), com um nível de base de cerca de $300 \mathrm{~m}$ de altitude.

A gênese e evolução dessa cuesta regional encontra-se associada aos processos de reativação tectônica mesozoica, com destaque para o Lineamento Transbrasiliano (Costa et al., 1991; SAADI et al, 2005), a partir de quando ficaram mais evidenciados os processos de subsidência do centro da Bacia Sedimentar do Parnaíba e a elevação de sua borda leste (MOURA-FÉ, 2016). As mudanças climáticas regionais Quaternárias também foram responsáveis tanto pela instalação de sistemas de erosão diferencial, como pelo desenvolvimento de processos de laterização em algumas áreas, favorecendo sua maior resistência àqueles sistemas que retrabalharam e moldaram as formas atuais do relevo, de forma geral, tanto em níveis regional/sub-regional, como locais (CRISTOFOLETTI, 1980). 
A base geológica do município de Pedro II, identificada em Brasil/CPRM (2006) indica que essa área foi submetida ao tectonismo mesozoico, evento este refletido nas linhas de falhamentos regionais e faturamentos locais, que apresentam direções predominantemente ortogonais, de NE-SW e NW-SE, preferencialmente na faixas do lineamento Transbrasiliano (SCHOBBENHAUS FILHO; CAMPOS, 1984; SAADI et al, 2005). Essas condições, possíveis de serem inferidas em trabalhos de campo, resultaram num intenso quebramento dessa estrutura sedimentar, que se reflete nas formas de relevo aí esculturadas e no encaixamento da drenagem, como mencionam vários estudos (LIMA, 1982; CUNHA, 1986; GOMES; CORTEZ, 2014; SACHS; BAPTISTA, 2015).

As morfoestruturas, como destacam Ross (2003) e Corrêa et al. (2010), respondem pelas formas do relevo de maior dimensão, tratadas em escala regional, enquanto as morfoesculturas correspondem ao modelado ou à tipologia de formas geradas sobre uma ou várias morfoestruturas através da ação exogenética, estando essas formas embutidas nas morfoestruturas apresentam, então, escala de detalhe. Desse modo, o entendimento das formas atuais do relevo sob o viés morfoestrutural passa por uma adequada interpretação das atuação de agentes endogenéticos e exogenéticos atuais e pretéritos e que deixam marcas na superfície do terreno, específicas de cada processo dominante. Considerando, pois, a gênese e evolução dessa cuesta regional, a ação milenar intensa desnudou seu reverso fazendo surgir uma cuesta de menores dimensões, a dos Matões, chamada localmente de Serra de Pedro II (ANDRADE; LINS, 1977). Lima (1987) classificou este planalto como uma unidade de relevo que compõe o compartimento regional do relevo Planalto Oriental da Bacia Sedimentar do Parnaíba, enquanto outra classificação mais recente não considera que Matões encontra-se como uma unidade dissecada do reverso regional da Ibiapaba, como um reafeiçoamento desta, portanto uma morfoescultura no contexto da evolução da morfoestrutura formada pela Ibiapaba, classificando-o como uma unidade local independente dessa morfoestrutura, mesmo se encontrando na porção superior desse reverso, ao nomeá-lo como um "planalto residual de pequenas dimensões, isolado do Planalto da Ibiapaba e localizado em meio à Superfície Aplainada da Bacia Sedimentar do Parnaíba" (FERREIRA E DANTAS, 2010, p.58).

Nessa área pode-se perceber a distribuição espacial e o contato das diferentes litologias que afloram nesse município (PIAUÍ/CPRM, 2006), representadas a leste pelas rochas mais antigas do Grupo Serra Grande, datadas do 
Siluriano, e a porção a oeste pelas rochas da formação Cabeças, de idade Devoniana, tendo entre dois capotes rochosos uma estreita faixa de norte a sul da formação Pimenteiras. Esta se encontra deprimida pela erosão diferencial, formando as depressões topográficas em toda a extensão de seu afloramento, compondo as depressões ortoclinais na base da cuesta dos Matões e se estendendo para além desse município.

Com relação à formação Longá, apenas pequenos manchas residuais na porção noroeste desse município, sobrepostas à formação Cabeças, porém apresentando menores altitudes, porque aflora na porção mediana do reverso regional da Ibiapaba, o qual decresce até a calha do rio Parnaíba acompanhando o mergulhos das camadas geológicas da Bacia Sedimentar do Parnaíba, conforme se observa no gráfico geológico-geomorfológico da Figura 2, e também na direção dos rios afluentes do Longá que têm suas nascentes nessa porção do relevo (Figura 3).

Figura 3 - Mapa geológico da área onde se encontra o município de Pedro II, Piauí
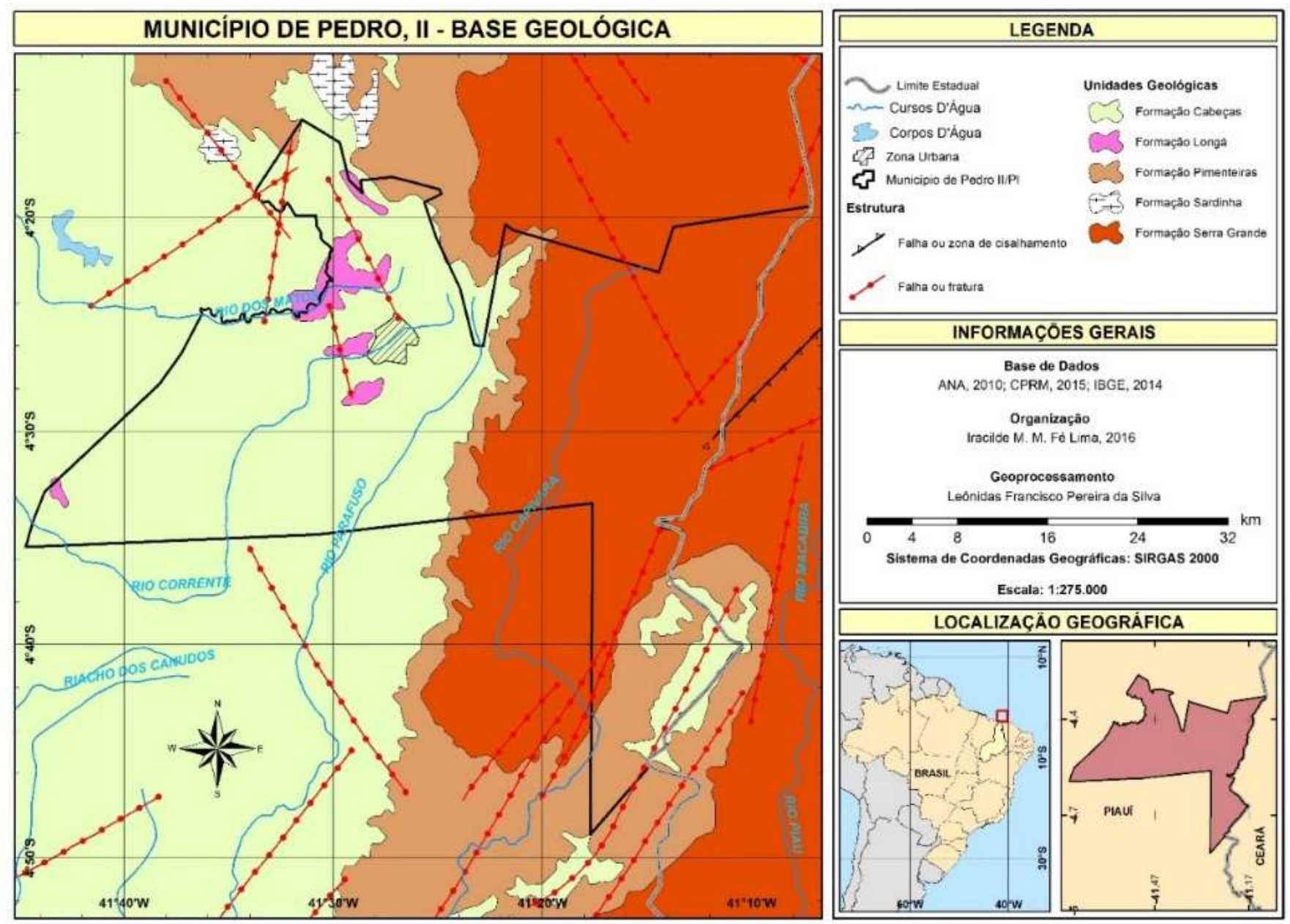

Base de dados: PIAUI/CPRM (2006); IBGE (2014). Org. Lima (2016). 
Essas características realçam a importância que tem a identificação das relações entre a estrutura geológica e as formas de relevo, uma vez que os falhamentos, juntas e sistemas de fraturas podem ser considerados como os principais elementos que resultaram de processos produtores dos arranjos estruturais. E estes, direta e indiretamente, atuam como condicionantes do relevo, tanto em pequenas quanto em grandes escalas, como destacam Casseti (2005) e Vervloet (2015). Já a composição rochosa da estrutura, que se encontra associada à sua gênese, vai se refletir na maior ou menor resistência aos processos erosivos, realçando as características da litologia pelos sistemas de erosão diferencial (desnudação) e modelando relevos de feições erosivas, deposicionais e residuais (AB'SABER, 1975; LEOPOLD et al., 1964). Os sedimentos transportados pela água causam também um outro tipo de reafeiçoamento no ambiente, que é denominado de offsite effect (efeitos fora do local onde ocorre a erosão). Isso pode corresponder a mais um aspecto da dinâmica local do ambiente a ser considerado pelas autoridades, devido à expansão do turismo na área de estudo (GUERRA, 2016).

O perfil geológico-geomorfológico, com extensão de cerca de $25 \mathrm{Km}$ (Figura 4), representa um transecto de direção NE/SE da área norte de Pedro II. Nele se observa a dissecação do reverso da cuesta local formado em rochas da formação Cabeças, onde o entalhamento de vales estruturais e fluviais faz aflorar manchas de diques associados a falhas locais e um extenso sill que se compõem de diabásios/basaltos (datados do Mesozoico) e nomeados como formação Sardinha. Pode-se perceber, ainda, pequeno trecho de uma depressão na base NE da cuesta/serra dos Matões, onde se observa na sua baixa vertente a posição da formação Pimenteiras sobreposta à formação Serra Grande e sotoposta à formação Cabeças, cuja porção mais elevada apresenta-se recoberta por camada laterítica (GOMES; CORTEZ, 2014). Indica, ainda, que nesta área foram evacuados espessos pacotes de rochas sedimentares, inclusive toda camada da formação pimenteiras, e intrusivas dessas formações geológicas, tendo o sistema erosivo sobrepujado a resistência das rochas, modelando assim o relevo atual.

Essa unidade de relevo também adquire grande importância por corresponder ao divisor topográfico de vários tributários dos rios Poti e Longá, ambos grandes afluentes do maior rio piauiense: o Parnaíba. Assim, vários riachos que aí têm suas nascentes são formados ora em zonas de fraturas e falhas geológicas verticais, ora na base de colúvios, ora nas áreas entre as base do arenito e/ou colúvio e o topo da soleira de diabásio da formação Mosquito, data do Mesozoico. 
Figura 4 - Perfil geológico-geomorfológico da área norte do município de Pedro II

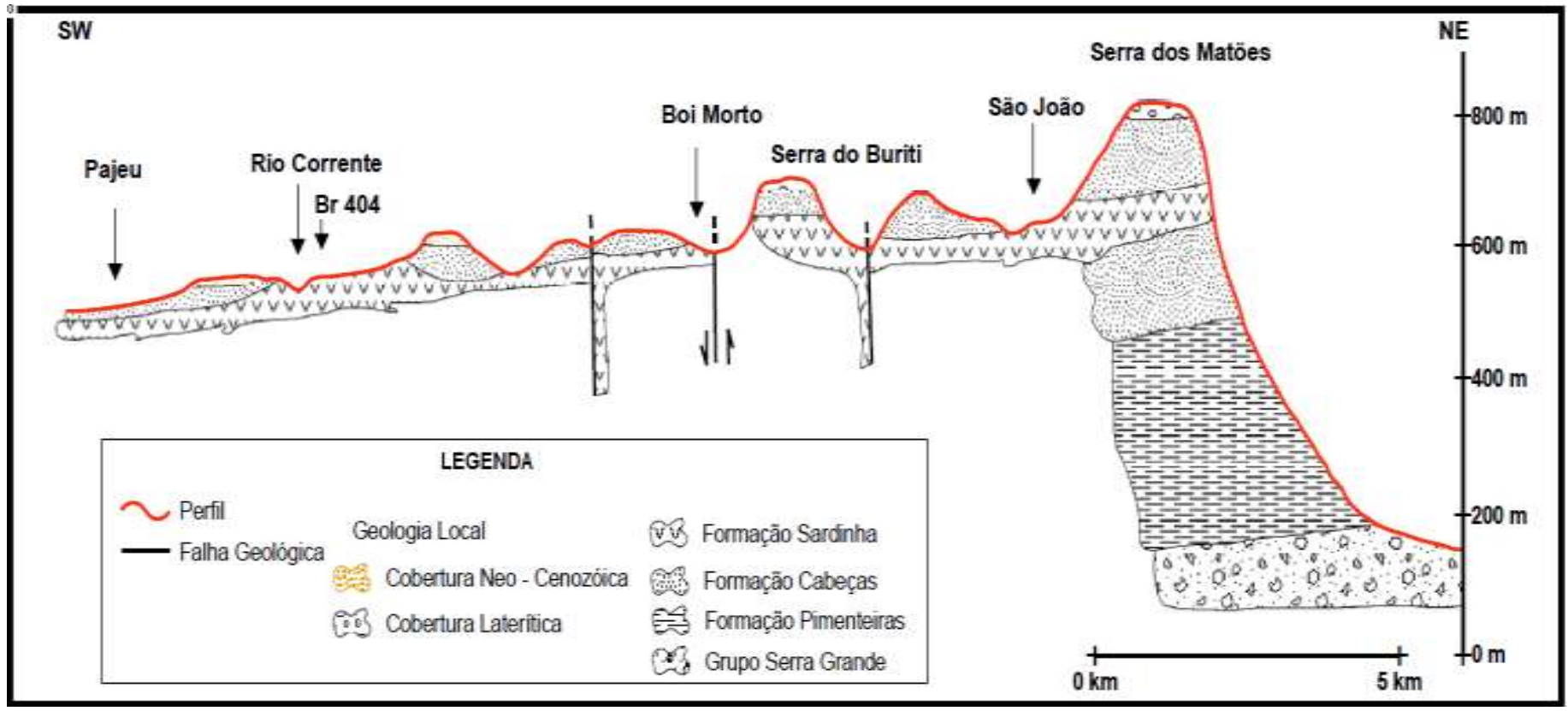

Fonte: Gomes e Cortez (2014); modificado de Rosa (1988).

Essa unidade de relevo também adquire grande importância por corresponder ao divisor topográfico de vários tributários dos rios Poti e Longá, ambos grandes afluentes do maior rio piauiense: o Parnaíba. Assim, vários riachos que aí têm suas nascentes são formados ora em zonas de fraturas e falhas geológicas verticais, ora na base de colúvios, ora nas áreas entre as base do arenito e/ou colúvio e o topo da soleira de diabásio da formação Mosquito (Mesozoico). Outros se formam, ainda, em zonas de contato entre os arenitos da formação Cabeças e as camadas de argilitos da formação Pimenteiras (GOMES; CORTEZ, 2014). A dinâmica desses riachos, ao contribuir para a dissecação do relevo local, vai realçando também degraus estruturais em alguns trechos onde se formam cachoeiras que chegam a mais de 30 $\mathrm{m}$ de quedas d'água.

$\mathrm{Na}$ Figura 5 encontra-se outra visão do relevo da cuesta dos Matões, observada do mirante do Morro do Gritador, onde se percebe com maior definição a seção da depressão voltada para nordeste, o front e o reverso imediato da cuesta, que nessa borda apresentam-se formando um arco voltado para leste/norte/noroeste. 
Figura 5 - Fotografia de uma seção do relevo de cuesta, vista do mirante do Morro do Gritador, Pedro II, Piauí.

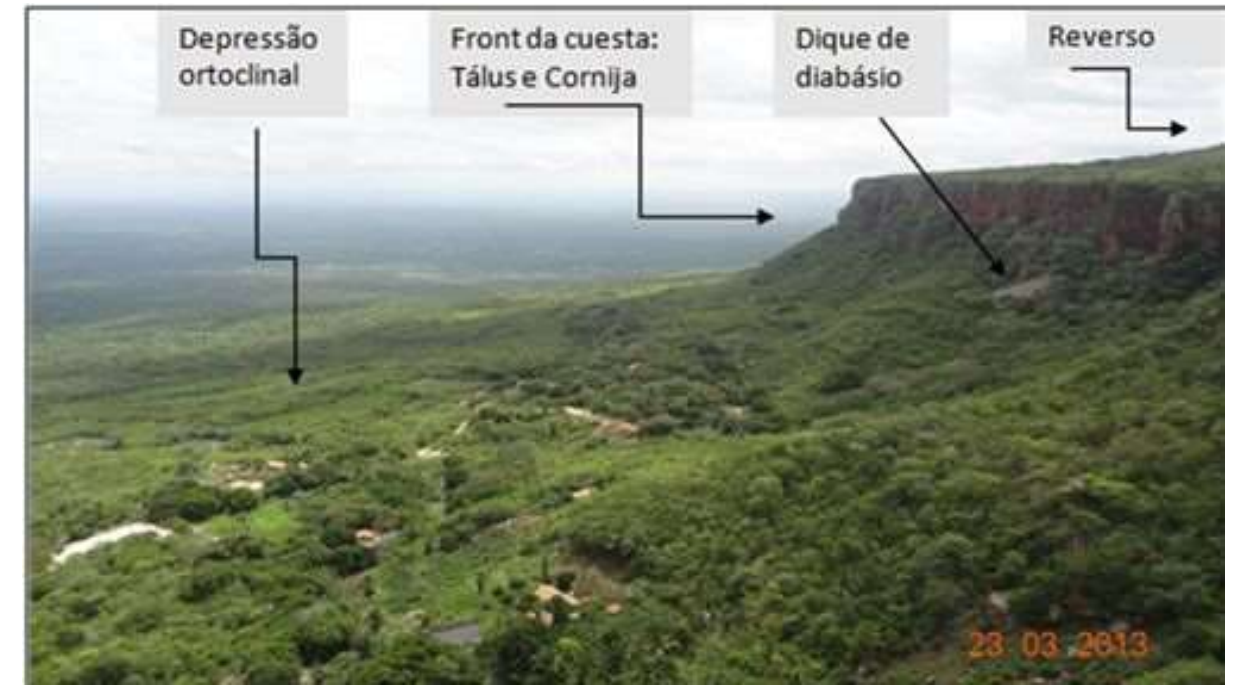

Foto: Lima (jun.2016).

Com relação à percée "o apertado da hora", corresponde à um tipo de vale bem encaixado: percée na nomenclatura geomorfológica (CASSETI, 2005). Este se encontra no front voltado para noroeste, ao lado do morro do Gritador, resultante do alargamento de uma das linhas de fraturas que orientam a evolução do desgaste da cuesta dos Matões, como se observa nas Figuras 6.

Figura 6 - Imagem da seção norte da cuesta dos Matões, o sistema de fraturas e a percée

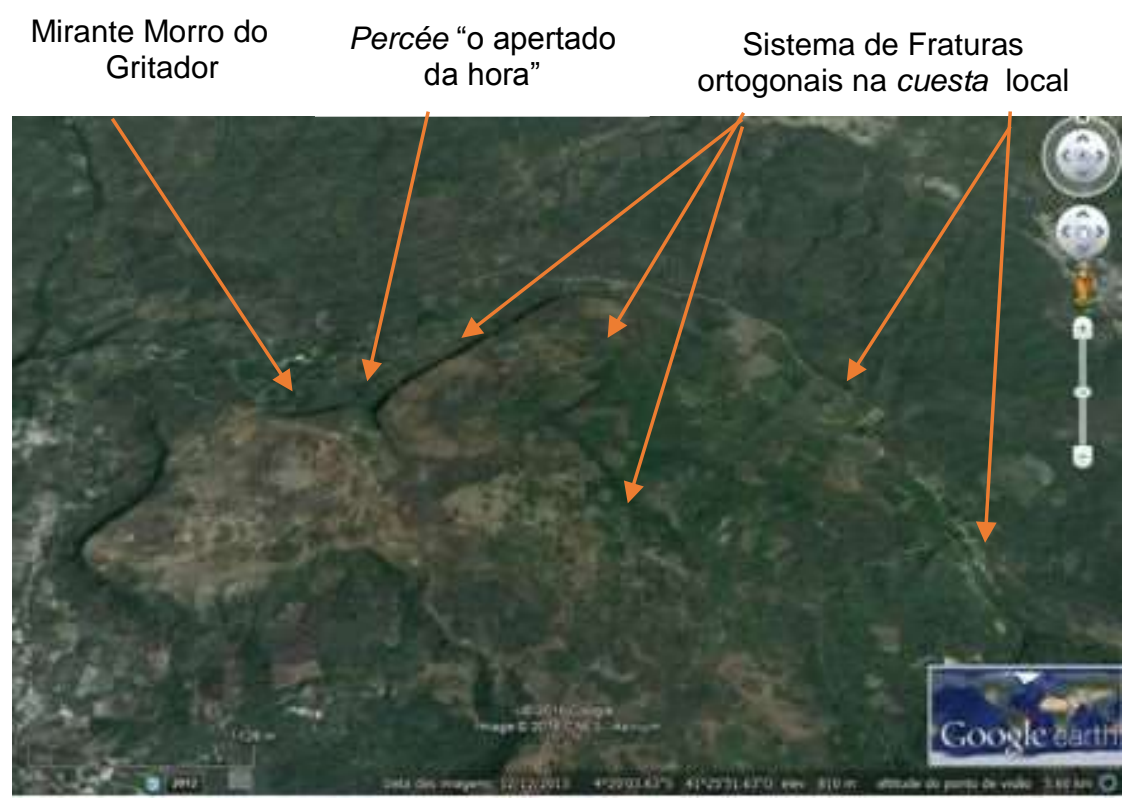

Fonte: Google Earth (imagem de 12.12.2013). 
Em trabalhos de campo pôde-se identificar que essa percée se formou a partir da atuação da erosão regressiva, decorrente do trabalho de um riacho de regime efêmero e de movimento de massa alargando uma das linha de fraturas do sistema de fraturamentos que atingiu a borda norte dessa cuesta, ou Serra dos Matões. Observou-se também que a abertura desse vale estrutural apresenta uma extensão de cerca de $350 \mathrm{~m}$, ampliando-se conforme maior ou menor intensidade dos deslizamentos e da queda de blocos no seu interior, tendo atualmente uma largura de aproximadamente $15 \mathrm{~m}$ no contato com a rampa de sedimentos (talus), como se observa no painel de fotos (Figura 7).

Figura 7 - Painel de fotografias da percée "o apertado da hora"
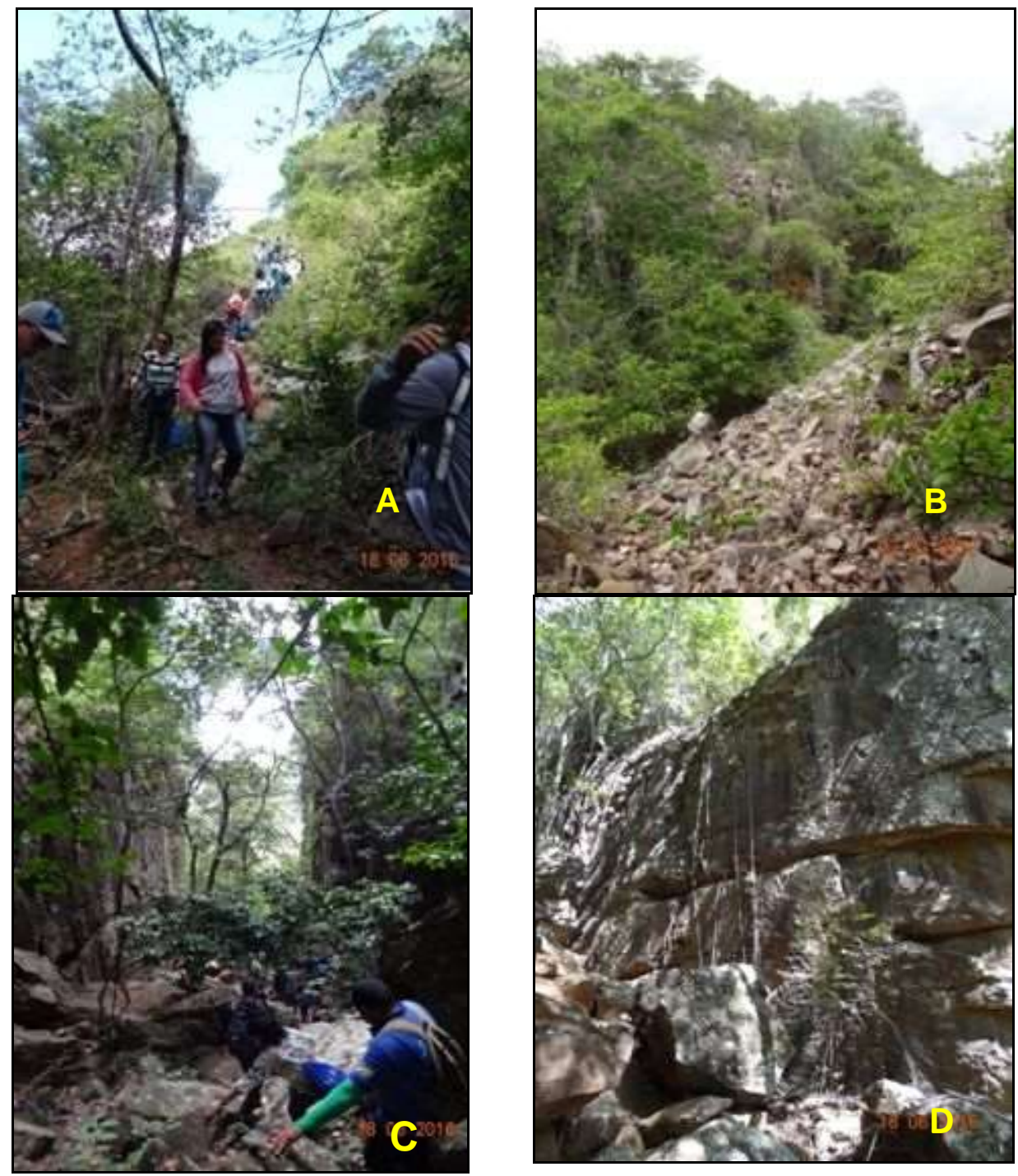

Legenda: A - Acesso à percée em aula prática; $\mathbf{B}$ - Deslizamento de blocos em trecho da alta vertente da percée; C - Blocos no interior e visão da "saída" da percée para a rampa dos depósitos de talus; D Vertente da percée com intenso fendilhamento (Fotos: Lima,jun.2014). 
Assim, considerando a altitude de $710 \mathrm{~m}$ para o topo da cornija nesse local, ou seja, da camada superficial de rochas areníticas mais resistentes à erosão, essa camada apresenta aí cerca de $40 \mathrm{~m}$ de espessura, a partir de onde passam a ser depositados os sedimentos provenientes de seu desgaste, fazendo-a recuar, mas mantendo sua forma escarpada. Já o dique de diabásio que aflora nesse talus se encontra a cerca de $620 \mathrm{~m}$ de altitude e a comunidade Caranguejo se situa a $490 \mathrm{~m}$ de altitude, instalada na área norte da depressão ortoclinal.

O processo de evolução da percée inferido pelo intenso movimento de massa, é representado pelos deslizamentos e quedas de blocos no seu interior, onde se encontra um significativo volume de blocos e matacões que chegam a medir até cerca de 3 metros. Nas vertentes íngremes de seu interior as rochas encontram-se intensamente fraturadas, como resultado da atuação de intensos processos de intemperismo, ampliando o fendilhamento e isolando blocos de rochas, demonstrando que está tendendo a um estado de equilíbrio instável na sua sustentação. O expressivo deslizamento mobiliza blocos de tamanhos variados, sendo a maioria variando de cerca de 5 a $20 \mathrm{~cm}$ no local de um dos acessos à essa percée utilizado pela população. Outra ação natural que participa do processo de evolução dessa forma de relevo é comandada pela formação de um riacho efêmero que escoa pelo interior da percée após as chuvas, remobilizando os sedimentos finos e até fazendo rolar grandes blocos em direção ao talus em anos de chuvas intensas, como ocorreu em 2009 (ACONTUR, 2016).

Sobre o uso dessa percée, identificou-se que a população local mantém com ela uma estreita relação, utilizando-a frequentemente como caminho entre as localidades do topo e aquelas situadas na depressão ortoclinal, formada a partir da base do front dessa cuesta. Destaque-se que, além de ser utilizado por adultos, esse caminho é percorrido diariamente pelos adolescentes e jovens que moram na comunidade Caranguejo, localizada na depressão à frente da percée, que vêm estudar nas escolas localizadas nas comunidades do topo do planalto dos Matões (ACONTUR, 2016).

\section{Atrativos Turísticos}

Alves et al. (2014-2015) comentam que o lazer em ambientes naturais e o desenvolvimento do ecoturismo resultam da procura por vivências e experiências em contato com a paisagem natural, como em parques e outras áreas verdes. No caso 
do município de Pedro II, além de áreas verdes, encontram-se vários outros elementos que atraem a visitação, tanto por se constituir numa região montanhosa de clima ameno, quanto pelo artesanato de fios de algodão e das peças de adorno utilizando a opala. No entanto, até o início da década de 2000 a visitação a esse município se caracterizava como espontânea, não tendo ainda a conotação de uma atividade turística por ainda ser incipiente e desestruturada. Essa afirmação se baseia no fato que até então as promoções de eventos e outras atrações, como em outros lugares piauienses, ocorria de forma pontual, geralmente em período de férias escolares. Recentemente, algumas iniciativas governamentais começaram a ser organizadas, mas ainda sem planejamento de ações integradas, nem preparação e/ou apoio à instalação de infraestrutura adequada/eficiente necessárias ao desenvolvimento das atividades turísticas.

Dentre essas iniciativas encontra-se o estabelecimento de "polos e roteiros" para o turismo, com base na classificação adotada pelo Plano Estratégico de Desenvolvimento Turístico do Piauí, em consonância com as diretrizes do Programa de Desenvolvimento do Turismo (PRODETUR-PI), que incluiu Pedro II no "polo costa do delta" (PIAUI, 2002). Assim, a partir de 2003 esse município passou a organizar o Festival de Jazz e Blues de Pedro II, conhecido como Festival de Inverno, que é realizado anualmente na semana em que se comemora o dia santo de Corpus Cristi, ou seja, final de maio/início de junho, com duração de quatro dias, conforme o calendário religioso (SANTIAGO, 2013).

No período desse festival outras atividades são incluídas no roteiro turístico local, envolvendo programações diurnas e noturnas, com visitas a paisagens naturais e culturais. Dentre os pontos mais visitados no ano de 2015, segundo a ACONTUR (2016), destacaram-se: o Mirante do Gritador, o Sítio Buritizinho e o Museu da Roça, seguidos de cachoeiras, principalmente a do Salto Liso. Outros pontos de atração correspondem ao Parque Pirapora, os sítios arqueológicos, as minas de extração de opalas, o Memorial Tertuliano Brandão, a arquitetura colonial de casarios, lojas de artesanato de fios de algodão que dão origem a tapeçarias e redes e, ainda, as peças de adornos pessoais utilizando pedras preciosas de opala, já conhecidas principalmente na região Nordeste do Brasil (Figura 8). 
Figura 8 - Painel de fotos de aspectos das atrações turísticas de Pedro II

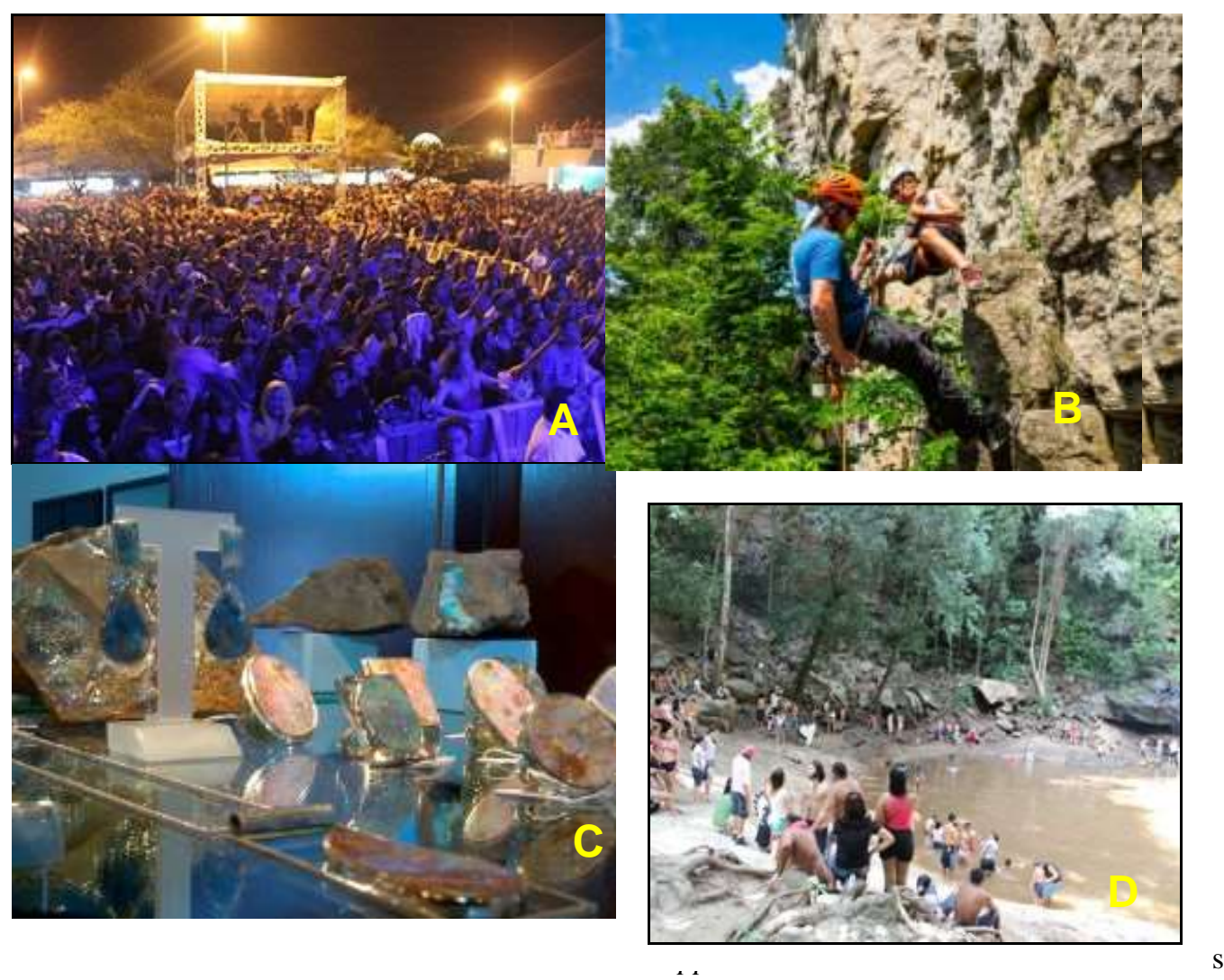

Legenda: A - Adornos artesanais em opala. Pedro II (Foto: Piauí/TV Clube, 2016); B - Rappel em vertente do Planalto dos Matões, Pedro II; C - Show durante o festival de Inverno em 2013,5, Pedro II; D - Banho no lago da cachoeira do Salto Liso, Pedro II (Fotos: Santiago, 2013/G1.globo.com).

A influência que tem a realização do Festival de Inverno para atrair pessoas a esse município é demonstrada através do levantamento do número de visitantes no ano de 2015. Identificou-se que nesse ano Pedro II recebeu cerca de 38.000 pessoas, sendo que 28.000 lá estiveram em junho, mês da realização do festival, enquanto o número de visitantes nos demais Meses do ano foi de cerca de 3.500 pessoas no período de janeiro a maio, e de 6.500 pessoas nos meses de julho a dezembro. Desta forma, excluindo-se o mês do festival, a média de visitação a Pedro II foi de apenas 900 pessoas/mês, aproximadamente (ACONTUR, 2016).

Com relação ao lugar de origem dos turistas, o levantamento de dados (ACONTUR, 2016), identificou que em 2015 cerca de $86 \%$ dos turistas eram provenientes de outros municípios piauienses, dos quais $60 \%$ de Teresina, capital do Piauí. Em relação aos 14\% restantes, $6 \%$ vieram do estado do Maranhão, 6\% eram de outros estados brasileiros e $2 \%$ oriundos de outros países, sendo o maior número dos EUA. 
Deve-se destacar, no entanto, que esse pode ser classificado como um tipo de turismo de massa, uma vez que, conforme Rejowski (2002), transfere poucas qualidades de compensação para a região receptiva, população ou base de recursos naturais, enquanto o tipo de turismo alternativo é aquele que se ramifica em formas que apresentam coerência com os valores natural e social/comunitário, possibilitando tanto o compartilhamento de experiências a hospedeiros e hóspedes, como também o desfrute de uma interação positiva e conveniente.

Sobre o turismo alternativo, Molina (2001) acrescenta que deve haver integração das comunidades locais com o desenvolvimento das atividades turísticas em áreas naturais, objetivando consolidar a sustentabilidade do ecoturismo em uma determinada região, em longo prazo. Essa condição é explicada por esse autor ao colocar que as comunidades locais devem atribuir um valor econômico ao ecoturismo, para evitar depredação e degradação das áreas naturais com potencial para o turismo. Como exemplo pode ser citado o Parque Pirapora, em Pedro II, onde o turismo

é realizado de forma pontual, sem planejamento e desrespeitando as leis ambientais, pois não há continuidade e muito menos fiscalização dos órgãos responsáveis pelo meio ambiente no município, nem tampouco pessoal capacitado para trabalhar a educação ambiental junto às comunidades do entorno do mesmo (GOMES, 2011, p.162).

Com a organização do Festival, continua este autor, esperava-se das autoridades maior empenho em adotar medidas eficazes envolvendo desde os cuidados com conservação do ambiente, a orientação à população local e aos visitantes, voltadas para o desenvolvimento dessa atividade de forma sustentável. No bojo do planejamento e gestão das atividades, necessário se faz, ainda, destaca essa autora, entre outras ações, a elaboração de estudos para identificação da capacidade suporte de cada um dos pontos turísticos, evitando sua depredação, ao mesmo tempo em que buscasse ampliar o crescimento econômico, acompanhado da minimização dos impactos ambientais negativos. Conforme Passold e Kinker (2010), a visitação pública possibilita o desenvolvimento do turismo local, regional e até nacional, mas deve envolver a participação das comunidades locais como atores, uma vez que estas correspondem a uma das principais geradoras de recursos. Deve, ainda, ser estruturada de forma a potencializar os benefícios sem interferir na implementação de outros programas e atividades de manejo, evitando impactos negativos sobre os recursos naturais e valores histórico culturais locais. 
Assim, considera-se que as atividades turísticas de Pedro II devam se organizar para atingir um nível de turismo alternativo, no sentido da concepção de Rejowski (2002), ou seja, levando em conta os aspectos relativos à necessidade de integração das comunidades e da conservação das riquezas naturais e da memória histórico-cultural. Essas condições certamente favoreceriam o desenvolvimento sustentável das atividades do ecoturismo e do turismo cultural, promovendo o desenvolvimento econômico e elevando ainda mais a autoestima da população local.

\section{Considerações Finais}

Com base na análise dos dados, mapeamentos e observações locais pode-se concluir que, mesmo com a atuação dos processos desnudacionais sobre a morfoestrutura da borda oriental da Bacia Sedimentar do Parnaíba, a herança geológica comanda a esculturação do relevo dessa área, observada no município de Pedro II, especialmente na cuesta dos Matões. Os registros desses eventos encontram-se evidenciados nos sistemas de fraturamentos presentes, principalmente nos altos topos esculpidos nas cuestas da lbiapaba e dos Matões; pela intrusão de rochas básicas; na formação da opala; na silicificação de rochas areníticas; em manchas de laterização hoje em desagregação mecânica e na organização da drenagem local.

Com relação ao relevo formado pela percée "o apertado da hora", observouse que a sua dinâmica natural resulta da ocorrência de movimentos de massa, evidenciados principalmente por deslizamentos e intensa queda de blocos no seu interior, aliados à erosão fluvial regressiva de um córrego de vazão efêmera. O seu expressivo recuo e alargamento revela que se encontra num estado de equilíbrio morfodinâmico instável, conforme a classificação de Tricart (1977). Com relação ao seu uso observou-se que existe entre a população local e essa forma de relevo uma relação de intimidade, por ser utilizada frequentemente como ligação que encurta o caminho entre o topo da cuesta dos Matões e a localidade Caranguejo, situada da depressão ortoclinal formada a partir da base do front, na porção inferior da rampa de colúvios.

Percebeu-se que o Mirante do Gritador se constitui um marco dentre os demais pontos de atração turística, tendo aumentado significativamente sua visibilidade e visitação a partir da realização anual do evento denominado Festival de Inverno de Pedro II. Assim, ao associar essas atividades ecológicas às culturais, 
o município de Pedro II passou a se caracterizar como um roteiro turístico piauiense de grande atração estadual, começando a ser conhecido nacionalmente, mas se enquadrando, ainda, na categoria de turismo de massa.

Torna-se necessário, então, que o poder público e a iniciativa privada empreendam um planejamento conjunto, nele envolvendo a população local, com ênfase num programa continuado de educação ambiental, para que o município possa assumir de forma consciente seu papel no processo de desenvolvimento sustentável local, tendo como um de seus sustentáculos a atividade turística.

\section{REFERÊNCIAS}

AB'SABER, A. N. Um conceito de Geomorfologia a serviço das pesquisas sobre o Quaternário. Noticia Geomorfológica. São Paulo: IG-USP, n. 19,1969.

AB'SABER, A. N. Formas de Relevo. São Paulo: Edart, 1975.

ACONTUR. Associação de Condutores de Turistas e Visitantes de Pedro II. Informações sobre pontos turísticos e visitantes de Pedro II. Pedro II: mímeo, 2016.

ANDRADE, G. O.; LINS, R. C. Bacia do Parnaíba: aspectos morfológicos. Recife: Fundação Joaquim Nabuco, 1977.

ALVES, C. J. S.; LARANJA, D. H. R.; RAIMUNDO, S. Lazer e Turismo e a prática do manejo e monitoramento da visitação pública como estratégia de gestão dos recursos no Parque Estadual da Cantareira (SP). Revista Brasileira de Ecoturismo, São Paulo, v.7, n.4, nov.2014-jan.2015, p.762-778.

BIZZI, L. A.; SCHOBBENHAUS, C.; VIDOTTI, R. M.; GONÇALVES, J. H. (Ed.). Geologia, Tectônica e Recursos Minerais do Brasil. Texto, Mapas e SIG. Brasília: CPRM, 2003.

BRASIL. Departamento Nacional de Produçâo Mineral. Projeto RADAM. Folha SB.23 Teresina e parte da folha SB.24 Jaguaribe; geologia, geomorfologia, solos, vegetacäo e uso potencial da terra (Levantamento de recursos naturais). Rio de Janeiro, 1973.

BRASIL. Ministério das Minas e Energia. Mapa Geológico do Estado do Piauí, 1:1.000.000. Teresina: CPRM/Governo do estado do Piauí, 2006.

CASSETI, V. Geomorfologia. 2005. Disponível em:

http://www.funape.org.br/geomorfologia/pdf/index.php Acesso em: 20 jan.2010.

CLAUDINO-SALES, V. Megageomorfologia do Estado do Ceará: história da paisagem geomorfológica. Saarbrücken: Novas Edições Acadêmicas, 2016.

CHRISTOFOLETTI, A. Geomorfologia. São Paulo: Edgard Blucher, 1980.

CORRÊA, A. C. B.; TAVARES, B. A. C.; MONTEIRO, K. A.; CAVALCANTI, L. C. S. e LIRA, D. R. Megageomorfologia e morfoestrutura do Planalto da Borborema.

Revista do Instituto Geológico, v. 31, n. 1/2, p. 35-52, 2010.

COSTA, J. B. S.; BORGES, M. S.; IGREJA, H. L. S.; HASUI, Y. Aspectos da

Evolução Tectônica da Bacia do Parnaíba e sua relação com o arcabouço Pré- 
Cambriano. In: SIMPÓSIO NACIONAL DE ESTUDOS TECTÔNICOS, 3. Rio Claro (SP), 1991, Boletim..., Rio Claro (SP), p.86-98, 1991.

CUNHA, F. M. B. Evolução Paleozoica da Bacia do Parnaíba e seu arcabouço tectônico. 1986. 107f. Dissertação (Mestrado). Programa de Pós-graduação em Geologia, Instituto de geociências, Universidade Federal do Rio de Janeiro, Rio de Janeiro, 1986.

FERREIRA, R. V.; DANTAS, M. E. Relevo. In: PFALTZGRAFF, P. A. S.; TORRES; F. S. M.; BRANDÃO, R. L. (org.). Geodiversidade do estado do Piauí. Recife: CPRM, 2010, p.45-84.

GOMES, D. O. B. Mineração, turismo e ambiente em Pedro II, Piauí. 2011. $281 f$. Tese (Doutorado). Programa de Pós-Graduação em Geografia. Universidade Estadual Paulista Júlio de Mesquita Filho. São Paulo, Rio Claro: UEPJMF: 2011.

GOMES, E. R.; CORTEZ, A. T. C. Gênese das nascentes encontradas no entorno da Serra dos Matões, Pedro II, Piauí. $47^{\circ}$ Congresso Brasileiro de Geologia. Anais... Salvador, BA, 2014.

GOMES, E. R.; CORTEZ, A. T. C.; COSTA, M. L. Contribuição à gênese das opalas de Pedro II, Piauí. In: Geochimica Brasililiense. Rio de Janeiro, v.8, n.1, 1994. Disponível em:

http://www.cmig.ufpa.br/index.php?option=com_content\&view=article\&id=281\&ltemid $=18$ Acesso em 26.10.2014.

GUERRA, A.J.T. Erosão dos Solos e Movimentos de Massa - abordagens Geográficas. Editora CRV, Curitiba, Paraná, 2016.

LEOPOLD, L. B; WOLMAN, M. G.; MILLER, J. P. Fluvial Processes in Geomorphology. San Francisco: Freeman, 1964.

LIMA, E. A. M.; LEITE, J. F. Projeto estudo Global dos Recursos Minerais da Bacia Sedimentar do Parnaíba: integração Geológico-Metalogenética. Etapa III. Relatório Final. Recife: DNPM/CPRM, 1978.

LIMA, I. M. M. F. Caracterização Geomorfológica da Bacia Hidrográfica do Poti. 106 f. 1982. Dissertação (Mestrado). Programa de Pós-Graduação em Geografia. Instituto de Geociências. Universidade Federal do Rio de Janeiro. Rio de Janeiro, 1982.

LIMA, I. M. M. F. Relevo do Piauí: uma proposta de classificação. Carta CEPRO. Teresina, v.12, n.2, Ago./dez, 1987, p.55-84. Cópia digitalizada disponível em: http://iracildefelima.webnode.com/ Acesso em: 10 jan. 2016.

LIMA, I. M. M. F. Relatórios de aulas práticas em Pedro II. Teresina: UFPI, 2000; 2002; 2004; 2006; 2008; 2015; 2016.

MOLINA, E. S. Turismo e Ecologia. Bauru (São Paulo): Ed. EDUSC, 2001.

MOURA-FÉ, M. M. Evolução geomorfológica da Ibiapaba Setentrional, Ceará, Brasil: Gênese. In: 11을 SINAGEO. Maringá (PR), 2016. Disponível em: http://www.sinageo.org.br/2016/anais.html. Acesso em: 10 ago.2017.

PASSOLD, A. J.; KINKER, S. M. S. Visitação sustentável em unidades de conservação. In: PHILIPPI JÚNIOR, Arlindo; RUSCHMANN, Doris van de Meene. Gestão ambiental e sustentabilidade no turismo. Barueri, São Paulo: Manole, 2010.

PIAUI. Governo do estado do Piauí/CPRM. Mapa Geológico do Estado do Piauí, 
1:1.000.000. Teresina: Serviço Geológico do Brasil (CPRM), 2ª ${ }^{\mathrm{a}}$ versão, 2006.

PIAUI. Governo do estado do Piauí/CPRM. Secretaria do Planejamento. Secretaria de Turismo do Piaui (PIENTUR). Guia Turístico do Estado do Piauí: Polos Turísticos e Roteiros. Teresina: Fundação CEPRO, 2002.

PIAUI. Governo do estado do Piauí/CPRM. TV CLUBE. Riquezas do Piauí - mostra a beleza e o potencial econômico da opala. Pedro Il, 27/05/2016. Disponível em:

http://g1.globo.com/pi/piaui/noticia/2016/05/riquezas-do-piaui-mostra-beleza-e-opotencial-economico-da-opala.html. Acesso em 10 out.2016.

REJOWSKI, M. (Org.). Turismo no percurso do tempo. São Paulo: Aleph, 2002.

ROSS, J. L. S. Geomorfologia: Ambiente e Planejamento. 7 ed. (Coleção Repensando a Geografia). São Paulo: Contexto, 2003.

SAADI, A.; BEZERRA, F. H. R.; COSTA, R. D.; IGREJA, H. L. S.; FRANZINELLI, E. Neotectônica da Plataforma Brasileira. In: SOUZA, C. R. de G.; SUGUIO, K.; OLIVEIRA, A. M.; OLIVEIRA, P. E. Quaternário do Brasil. Ribeirão Preto: Holos Ed., 2005, p. 211-234.

SACHS, L.L. B.; BATISTA, I. H. (Org.). Projeto avaliação dos depósitos de opalas de Pedro II: estado do Piauí. Série Pedras Preciosas, n.8. Teresina: CPRM, 2015.

SANTIAGO, P. Cachoeira do Salto Liso em Pedro II no PI reúne beleza e esportes radicais. In: http://g1.globo.com/pi/. Pedro II, 2013. Disponível em: http://g1.globo.com/pi/piaui/noticia/2013/06/cachoeira-do-salto-liso-em-pedro-ii-no-pireune-beleza-e-esportes-radicais.html Acesso em 20 jun.2016.

SCHOBBENHAUS FILHO, C.; CAMPOS, D. A. A evolução da plataforma SulAmericana no Brasil e suas principais concentrações minerais. In:

SCHOBBENHAUS FILHO, C.; CAMPOS, D. A.; DERZE, G. R.; ASMUS, H. E. Geologia do Brasil: texto explicativo do mapa geológico do Brasil e da área oceânica adjacente incluindo depósitos minerais, escala 1:250.000. Brasília: DNPM, 1984, p. 9-49.

VIEIRA, C. I. P.; LIMA, I. M. M. F.; VIANA, B. A. S. Turismo cultural e ecológico em Pedro II, Piauí. In: $3^{\circ}$ Congresso Internacional de História e Patrimônio Cultural. Patrimônio, Sociedade e Museus. Parnaíba(PI), ago.2012.

TRICART, J. Ecodinâmica. Rio de Janeiro: IBGE, 1977.

VERVLOET, R. J. H. M. Elementos de Geomorfologia Estrutural: estudo aplicado a região serrana do Espírito Santo. 1a. ed. Vitória, ES: Ed. do autor, 2015.

\section{NOTAS DE AUTOR}

\section{CONTRIBUIÇÃO DE AUTORIA}

Iracilde Maria de Moura Fé Lima - Concepção. Elaboração do manuscrito, revisão e aprovação da versão final do trabalho

Antônio José Teixeira Guerra -Participação ativa da discussão dos resultados; Revisão e aprovação da versão final do trabalho.

FINANCIAMENTO

Não se aplica.

CONSENTIMENTO DE USO DE IMAGEM

Não se aplica. 
APROVAÇÃO DE COMITÊ DE ÉTICA EM PESQUISA

Não se aplica.

\section{CONFLITO DE INTERESSES}

Não se aplica.

\section{LICENÇA DE USO}

Este artigo está licenciado sob a Licença Creative Commons CC-BY. Com essa licença você pode compartilhar, adaptar, criar para qualquer fim, desde que atribua a autoria da obra.

\section{HISTÓRICO}

Recebido em: 08-11-2018

Aprovado em: 14-10-2019 